\title{
Price Dispersion and the Border Effect*
}

\author{
Ryan Chahrour Luminita Stevens \\ Boston College University of Maryland
}

January 29, 2019

\begin{abstract}
We find that observed cross-country price differences primarily reflect regional market segmentation occurring within countries. Using a model of price setting subject to costly search, we show that identification of national versus regional segmentation requires augmenting price data with regional trade flow data. Calibrating the model to data from U.S. and Canadian regions, we estimate substantial regional trade frictions: U.S. producers are three times more likely to sell to retailers in their own region than in the "away" region of the United States, and only slightly less likely to sell to a region in Canada, controlling for market size differences. Canadian producers have an even stronger home bias: they are seven times more likely to sell in their own region than in the "away" region in Canada, and 11 times more likely to sell in their own region than in a U.S. region. Models that do not explicitly account for regional home bias can misstate the severity of segmentation at the national border.
\end{abstract}

Keywords: Law of one price, Real exchange rates, Trade barriers, Home bias JEL Codes: F41, F30, E30

\footnotetext{
${ }^{*}$ We would like to thank Emi Nakamura, Jaromir Nosal, John Shea, Jón Steinsson, Rosen Valchev, and seminar participants at the Federal Reserve Bank of Boston, Boston College, and Columbia University for very helpful comments. We are grateful to João Ayres for excellent research assistance. Contact: ryan.chahrour@bc.edu and stevens@econ.umd.edu.
} 


\section{Introduction}

A large literature in international macroeconomics has sought to measure the frictions that hinder the flow of goods across countries. The seminal paper of Engel and Rogers (1996) used semi-aggregated price indices for goods sold in the United States and Canada to document significant border frictions. Subsequent work has sought to refine the estimates of the severity of trade frictions between countries using increasingly detailed datasets with prices at the product level. Empirical work by Gopinath, Gourinchas, Hsieh, and Li (2011), Burstein and Jaimovich (2012), Broda and Weinstein (2008), and Crucini and Telmer (2012) has documented that product-level price data across countries is consistent with a very large degree of segmentation at the national border. Following Gorodnichenko and Tesar (2009)'s criticism of reduced-form treatment of cross-border price data and their call for a more structural approach, the empirical evidence has been complemented by structural work reinforcing the conclusion that high cross-country market segmentation is crucial for generating realistic patterns for good-level violations of the law of one price.

We demonstrate the existence of an identification problem - even within structural frameworks - in distinguishing between market segmentation that is induced by the international border and background market segmentation that exists between regions or markets within a country. We show, in the context of a two-country multi-region model of trade, that cross-country price and trade data are not sufficient for determining whether international price dispersion arises from a friction inhibiting trade across countries or a friction that inhibits trade at the subnational level, across regions. We also show that the addition of data on regional trade patterns is precisely what is needed to separately identify the parameters governing within- and across-country segmentation, and we provide estimates for these two layers of frictions for trade between the United States and Canada.

Our central finding is that the evidence of good-level price dispersion combined with information on regional trade flows indicate that much of the measured market segmentation occurs at the subnational regional level. To arrive at this result, we 
calibrate our model to match a set of facts regarding good-level violations of the law of one price across the United States-Canada border, as well as both international and internal levels of trade for the two countries. We show that the model is very successful in matching the empirical patterns of violations of the law of one price and can simultaneously match the observed levels of trade both within and across Canada and the United States. Matching both sets of facts simultaneously, however, requires a calibration of the economy in which regional markets are strongly segmented, but there is only limited additional segmentation at the national border.

We obtain our results using a search-based model of international trade in which retailers engage in costly sequential search for the best price among the producers selling a particular good in the retailers' local markets. The search friction, combined with a distribution of producer-specific productivity shocks, gives rise to endogenous price dispersion in equilibrium. We focus on search frictions in our model of trade motivated by evidence that the prices of identical goods (measured at the barcode level) vary substantially not only across national borders, but also across regions of the same country and indeed even within the same region or market. The fact that significant price dispersion can be sustained at the local level is relevant for measuring the severity of international border frictions because, as demonstrated by Gorodnichenko and Tesar (2009), the existence of price dispersion within countries can bias estimates of the "size of the border" that are derived in a reduced-form framework that measures only price dispersion across countries.

We augment the basic search model with an export bias parameter that captures the probability that a producer headquartered in a particular market has the option to set up shop and try to sell in another market, controlling for relative market size. This feature allows us to go beyond the existing literature and explicitly quantify the degree of domestic and international market segmentation, while also accounting for differential trade patterns that reflect market size differences. The model nests regionally and nationally segmented markets. Under regional segmentation, producers headquartered in one region are less likely to set up shop in other regions, while under national seg- 
mentation, producers are equally likely to set up shop in the regions within their own country, but less likely to set up shop in the other country. We use price and quantity data to obtain estimates of the size of these relative biases, which pin down the regional versus national border frictions in our model.

Applied to United States and Canada data, our model implies that to a large extent, the apparent segmentation at the national border is in fact a reflection of regional segmentation. Splitting the United States in two equal-sized regions, we estimate that on average producers are three times more likely to sell to retailers in their own region than to retailers in the "away" U.S. region. Hence, there are significant barriers to the flow of goods across U.S. regions. Crossing the national border further reduces access, but this barrier is less severe than the regional barrier, with American producers being only $23 \%$ more likely to sell in the "away" domestic region than to a Canadian region.

Furthermore, we uncover substantial asymmetry across countries in the severity of these frictions. Canadian producers are seven times more likely to sell in their own region than in the "away" Canadian region, and 11 times more likely to sell in their own region than in an American region. Overall, regional bias is a major component of the national home bias, and it appears more severe for Canadian producers. In a counterfactual exercise, we show that the data are not far from a parameterization in which all segmentation comes from regional, rather than national frictions.

Our measures of relative bias provide a simple way to parameterize all the frictions and barriers to trade, either bilateral or unilateral, which may affect the likelihood of transacting across regions. They may be a stand-in for informational advantages that ease access to the chain of production in one's own market, or for external barriers that make transacting with firms located outside one's own network more difficult. Together with the size of each market, the segmentation parameters determine how producers are matched with the retailers of different regions, and hence the distribution of prices available in each region. Together with the search friction, they generate pricing to market, as producers may charge different prices to customers located in different regions, depending on local demand conditions and competitive pressures. In 
our model, pricing to market plays a very important role in explaining cross-border price differential, consistent with the empirical evidence emphasized by Burstein and Gopinath (2014).

Our paper relates to an extensive literature examining violations of the law of one price, which has been surveyed recently by Burstein and Gopinath (2014). Alessandria (2004, 2009) and Alessandria and Kaboski (2011) also use a search friction to motivate cross-border price differences, although these papers do not emphasize the distinction between frictions that occur across markets within countries versus those that occur at the border. On the other hand, for alternative search-theoretic models of the product market that focus on price dispersion across stores in a given market, see Kaplan and Menzio (2015), Menzio and Trachter (2015), and Menzio and Trachter (2018).

Our modeling approach also resembles that of Gopinath et al. (2011) and Burstein and Jaimovich (2012) in that we consider a model with a real friction in goods markets, coupled with country heterogeneity in the distribution of firm costs. In addition to the papers cited earlier, recent related papers using micro-level price data include Baxter and Landry (2012), Goldberg and Hellerstein (2013), Fitzgerald and Haller (2014), and De Loecker, Goldberg, Khandelwal, and Pavcnik (2015). A related literature, including Atkeson and Burstein (2008), Drozd and Nosal (2012) and Candian (2015), also studies failures of purchasing power parity in more aggregate - and dynamic - contexts.

Burstein and Jaimovich (2012) also introduce within-country regions in their economy and point out an identification problem using prices alone to distinguish between (i) differences in demand-shock correlations across within-country and across-country region pairs and (ii) differences in markup elasticities. However, the problem we highlight is distinct. The forces they discuss are the two forces in their model that can generate within-country price dispersion, and map to the sources of within-region price dispersion in our economy. ${ }^{1}$ We implicitly break their identification problem by assuming perfect correlation of demand conditions within countries, but show there is nevertheless an identification problem regarding the source of market segmentation.

\footnotetext{
${ }^{1}$ Prices are dispersed within regions in our economy, but not in Burstein and Jaimovich (2012).
} 
Methodologically, our paper is distinct from the earlier literature because it incorporates price and quantity data simultaneously. An exception is Boivin, Clark, and Vincent (2012), who consider price and quantity data using a good-level data set for a retailer in the online book market and find substantial deviations both within and across countries. Although their exercise is nonstructural, these authors also note a challenge in identifying market segmentation induced by the border from the segmentation that gives rise to price dispersion within countries.

The results in this paper are also related to an extensive literature studying the effects of national and subnational borders using gravity models of trade quantities. McCallum (1995) finds extremely that large effects of the international border are required to account for within- and across-country trades levels between the United States and Canada. Anderson and van Wincoop (2003) show that the estimated border effect on trade is much smaller once theoretically motivated measures of multilateral resistance are added to the estimation. Wolf (2000) focuses particularly on the effect of intranational borders and finds evidence of substantial barriers to trade. His results are largely corroborated by Millimet and Osang (2007), who argue the effects can be accounted for by historical patterns of migration and past trade. Other related papers along this line include Chen (2004) and Hillberry and Hummels (2008).

Section 2 presents a search model of price dispersion and analyzes the problem of identifying regional versus national market segmentation. Section 3 calibrates the model and presents our estimates for the severity of internal and international trade frictions. Section 4 presents robustness and Section 5 concludes.

\section{Model}

We develop a multi-region, multi-sector two-country model in which search frictions generate price dispersion both within and across regions. We model the search friction as in Reinganum (1979), whose model of homogeneous buyers and heterogeneous sellers we expand to a general equilibrium framework with producers, retailers and consumers. 
We then extend the model to a two-country world with two regions in each country, featuring producers selling the same good at different prices in different regions.

\subsection{Single-Region Economy}

The economy features a representative consumer, a perfectly competitive nontradable sector, and a monopolistically competitive tradable goods sector. We focus on the tradable goods sector, since the puzzle is that the law of one price also fails to hold for traded goods, for which arbitrage should — but does not - eliminate price differences.

Consumers: The representative consumer buys goods in sectors $N$ and $T$ (which represent the nontradable and tradable sectors in the two-country model) and supplies labor. The consumer solves an optimization problem given by

$$
\begin{gathered}
\max _{C_{T}, C_{N}, L} \log \left(C_{T}^{\phi} C_{N}^{1-\phi}\right)-\psi \frac{L^{1+v}}{1+v} \\
P_{T} C_{T}+P_{N} C_{N} \leq W L+\Pi
\end{gathered}
$$

where $C_{N}$ and $C_{T}$ denote aggregate consumption in the two sectors, $P_{N}$ and $P_{T}$ are the respective price indices, $L$ is labor supply, $W$ the economy-wide nominal wage, and $\Pi$ nominal firm profits. The parameter $\phi \in(0,1)$ governs the share of sector $T$ in consumption, and $\nu>0$ is the inverse of the Frisch elasticity of labor supply. Consumer optimization implies that expenditure is allocated across the two sectors according to

$$
\frac{P_{T} C_{T}}{P_{N} C_{N}}=\frac{\phi}{1-\phi} .
$$

Labor supply is given by

$$
L^{\nu}=\frac{\phi W}{\psi P_{T} C_{T}}
$$

Sector $T$ is monopolistically competitive, with a continuum of goods indexed by $i$ and a continuum of varieties $\nu$ for each good. At each level, consumption is aggregated 
according to a constant elasticity aggregator,

$$
\begin{gathered}
C_{T}=\left(\int_{0}^{1} c(i)^{\frac{\rho-1}{\rho}} d i\right)^{\frac{\rho}{\rho-1}}, \\
c(i)=\left(\int_{0}^{1} c(i, \nu)^{\frac{\eta-1}{\eta}} d \nu\right)^{\frac{\eta}{\eta-1}},
\end{gathered}
$$

where $\rho>1$ is the elasticity of substitution across goods and $\eta>\rho$ is the elasticity of substitution across the varieties of each good. The associated price indices are $P_{T} \equiv\left(\int_{0}^{1} p(i)^{1-\rho} d i\right)^{\frac{1}{1-\rho}}$ and $p(i) \equiv\left(\int_{0}^{1} p(i, \nu)^{1-\eta} d \nu\right)^{\frac{1}{1-\eta}}$.

Demand at the variety and good level is given by

$$
\begin{gathered}
c(i, \nu)=p(i, \nu)^{-\eta} p(i)^{\eta} c(i), \\
c(i)=p(i)^{-\rho} P_{T}^{\rho} C_{T} .
\end{gathered}
$$

Sector $N$ is perfectly competitive, with a homogeneous good and a representative firm in that sector.

Retailers: A unit mass of multi-product retailers indexed by $\nu$ search for goods on behalf of consumers. Retailers know the distribution of prices posted by the producers (or distributors) of each good, but they do not know which producer sells at what price. Instead, they must pay a fixed search cost in order to meet a producer to sample from the distribution of producer prices. Upon sampling a producer, each retailer can purchase all of its demand at the sampled price or pay the search cost again to draw a new producer. Search continues until each retailer has settled on a single supplier for each good. Having settled on a supplier for each good, the retailer costlessly differentiates good $i$ into a retailer-specific good-variety, indexed by $(i, \nu)$, and sells it to the end consumer.

Placing the search friction at the retailer level is motivated by the evidence of Goldberg and Hellerstein (2008) and Gopinath et al. (2011) that retail markups do not vary much with nominal exchange rates, of Goldberg and Hellerstein (2013) and Eichen- 
baum, Jaimovich, and Rebelo (2011) that retail-level price changes follow changes in wholesale costs, of Berger, Faust, Rogers, and Steverson (2012) that overall "distribution wedges" are stable over time, and the finding of Hillberry and Hummels (2003) that intra-national trade bias is especially strong for wholesalers, who are the direct suppliers of retail outlets. We abstract from the local cost component by assuming that retailers costlessly differentiate goods because prior work has found that such costs are also insensitive to exchange rate movements.

The retailer is a price setter with elastic demand in the market for each good-variety and chooses a price schedule $p(i, \nu)$ to maximize total per-period profits

$$
\begin{aligned}
\pi^{R}(\nu) & =\int_{0}^{1} \pi^{r}(i, \nu) d i \\
\pi^{r}(i, \nu) & =[p(i, \nu)-\widehat{p}(i, \nu)] c(i, \nu)-\kappa n(i, \nu) .
\end{aligned}
$$

The price $\widehat{p}(i, \nu)$ is the producer price upon which the retailer $\nu$ settles after completing the search for good $i$ in the period, $c(i, \nu)$ is the quantity demanded, given by equation $(7), \kappa>0$ is the fixed cost per search, and $n(i, \nu)$ is the total number of times that the retailer searches for a potential supplier of good $i$.

The search process is independent across goods (since we assume that there are different suppliers for different goods) and each retailer's variety competes with the varieties of the same good from other retailers. As a result, the retailer does not internalize any impact of the price of one good-variety $(i, \nu)$ on the demand for its variety of other goods, $\left(i^{\prime}, \nu\right)$ and maximizes profits good by good.

For each good, the sequential nature of search implies that a retailer's choice to continue looking for a better price is independent of the number of producers already sampled. Given the currently sampled price $\widehat{p}_{i}$ and the distribution $f_{i}$ of producer prices that the retailer samples from, the retailer's value function for each good is

$$
V\left(\widehat{p}_{i} ; f_{i}\right)=\max \left\{V^{s}\left(f_{i}\right), V^{n s}\left(\widehat{p}_{i}\right)\right\}
$$


where the value of continuing to search for a producer net of the search cost is

$$
V^{s}\left(f_{i}\right)=\int V\left(\widehat{p} ; f_{i}\right) f_{i}(\widehat{p}) d \widehat{p}-\kappa
$$

integrating over the distribution $f_{i}$ of prices posted by active firms whom firm $i$ could possible encounter.

The value of halting the search and purchasing all demand from the currently sampled producer is

$$
V^{n s}(\widehat{p})=\max _{p} \pi^{r}(p, \widehat{p})
$$

where, with a slight abuse of notation, the function $\pi^{r}(p, \widehat{p})$ now denotes the profit that the retailer makes on a good if it buys it at price $\widehat{p}$ and sells it at price $p$. Since differentiation of each good at the retail level is costless, the retailer maximizes expression (13) by charging a constant markup over the supplier's price, $p=\mu \widehat{p}$, with $\mu \equiv \eta /(\eta-1)$.

The retailer continues to search for a supplier as long as the expected gain from doing so is positive. The optimal search strategy is a stopping rule described by a unique reservation price $\bar{r}_{i}$ for each good $i$ that equates the value of searching to that of stopping the search. All retailers sampling a price less than or equal to this threshold stop searching and purchase all their demand for good $i$ at the sampled price; all retailers sampling a price above it continue to search for a better offer.

Producers: For each good $i$, there is a unit mass of potential producers $j$ characterized by the production function

$$
y_{i j}=A_{i j} h_{i j}
$$

where $A_{i j}$ is idiosyncratic productivity and $h_{i j}$ is the labor input.

Each producer potentially sells to multiple retailers. Since the producer does not engage in price discrimination among the retailers in a given market and since retailers are symmetric, each retailer who settles on a given producer demands the same quantity,

$$
d_{i j}=\widehat{p}_{i j}^{-\eta} \widehat{p}_{i}^{\eta} c_{i}
$$


Letting $\chi_{i j}$ denote the mass of retailers who settle on producer $j$, a producer setting price $\widehat{p}(i, j)$ faces total demand

$$
x_{i j}=\left\{\begin{array}{lll}
\chi_{i j} d_{i j} & \text { if } & \widehat{p}_{i j} \leq \bar{r}_{i} \\
0 & \text { if } & \widehat{p}_{i j}>\bar{r}_{i}
\end{array} .\right.
$$

The producer's optimal price is then a constant markup over marginal cost, up to the retailers' reservation price:

$$
\widehat{p}_{i j}=\min \left\{\mu \tilde{w}_{i j}, \bar{r}_{i}\right\}
$$

where $\tilde{w}_{i j}=W / A_{i j}$ is the producer's marginal cost and $\mu$ is the markup. Since the retailer's search is undirected, the producer cannot use price to affect the mass of customers $\chi_{i j}$. However, since the demand from each retailer is elastic, lower-cost producers choose to charge prices below the reservation price to capture additional demand from each customer.

Search Equilibrium: An equilibrium in the producer-retailer market for good $i$ is a retail reservation price $\bar{r}_{i}$ and a distribution of producer prices $f_{i}$ such that (a) given $f_{i}$, retailers choose the optimal stopping rule governed by $\bar{r}_{i}$ and (b) given $\bar{r}_{i}$, producers maximizing profits generate $f_{i}$.

In this single market model, there is a unique reservation price and the retailers' stopping rule implies that there is no search in equilibrium, since all producers post prices that are weakly below this reservation price. Producers with marginal costs above the reservation price of the retailers would make negative profits, hence they shut down.

Let the cumulative distribution of marginal costs across producers of good $i$ be denoted by $G_{i}(\tilde{w})$. The resulting cumulative distribution of producer prices is given by

$$
F_{i}(\widehat{p})=\left\{\begin{array}{lll}
G_{i}\left(\frac{\widehat{p}}{\mu}\right) & \text { if } & \widehat{p} \leq \bar{r}_{i} \\
1 & \text { if } & \widehat{p}>\bar{r}_{i}
\end{array}\right.
$$


Since there is a unit mass of retailers and a unit mass of potential producers, the mass of retailers per active producer of each good $i$ is then given by

$$
\chi_{i}=\frac{1}{1-G_{i}\left(\bar{r}_{i}\right)}
$$

In models of search with homogeneous goods, arbitrarily small search costs can result in a collapse of the price distribution at the monopoly price (the Diamond (1971) paradox). In our setting, heterogeneous production costs together with elastic demand ensure that the distribution of prices is non-degenerate, as shown by Reinganum (1979) for a single market with many buyers and sellers. The degree of dispersion in prices depends on the cross-sectional dispersion of producer costs, and the out-of-equilibrium threat of search leads to incomplete pass-through of marginal cost for high-cost producers: markups are constant for all producers with marginal costs less than $\bar{r}_{i} / \mu$, and are decreasing in costs for active producers with costs above this threshold. ${ }^{2}$

\subsection{Multi-Region Economy}

We now extend the model to a multi-region setup with two countries, United States and Canada, and four regions, $a$ and $b$ in the U.S. and $c$ and $d$ in Canada. This extension enables us to introduce asymmetries across different regions and to generate pricing-tomarket, where a given producer charges different prices to retailers located in different regions. The two countries differ along multiple dimensions: size, the severity of trade and search frictions, the realization of the aggregate shocks, and the distribution of idiosyncratic productivity shocks. To reduce notation, we drop the good subscript $i$ wherever there is no confusion.

Market Segmentation: The degree of integration between regions can be affected by various potential frictions, either bilateral or unilateral, that make transacting across regions less likely than within regions, thereby leading to a home bias. This bias can

\footnotetext{
${ }^{2}$ Alternative ways to break the Diamond paradox include heterogeneity in consumer search costs, preferences or information sets (e.g., Salop and Stiglitz (1977)) and non-sequential search (Burdett and Judd (1983)).
} 


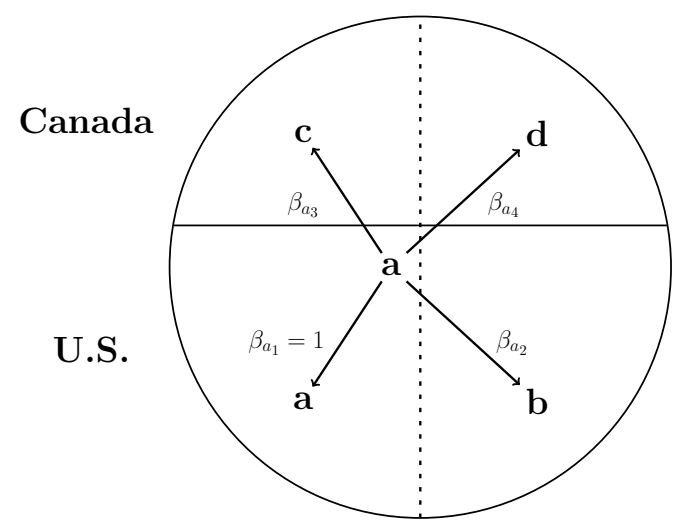

Figure 1: The two-country setup with two regions in each country. The bias rates for producers from region $a$ are $\beta_{a k}$ for $k \in 1,2,3,4$.

also depend on differences in market sizes, both in terms of the size of the customer base and in terms of the mass of producers who can potentially meet that demand.

Let the export potential of one region to another be $m_{r k}$, denoting the mass of producers headquartered in region $r$ who are potentially active ex-ante in relative region $k$ (though some may choose not to be active ex-post, depending on the prevailing prices in that market). In this notation, the letter $r \in\{a, b, c, d\}$ represents a region's absolute index while the integer $k \in\{1,2,3,4\}$ indexes relative regions. The relative index 1 indexes the region itself, 2 indexes the other region in the same country, and indices $k \in\{3,4\}$ always index the regions of the other country.

Let the export potential of region $r$ towards relative region $k$ take the functional form

$$
m_{r k}=\frac{\beta_{r k} s_{r} s_{\omega(r, k)}}{s_{r}+s_{\omega(r, k)}},
$$

where $\beta_{r k} \in[0,1]$ is a bias parameter specific to each source-destination pair, $s_{r}$ denotes the size of the market in region $r$, and the function $\omega(r, k)$ maps region $r$ to its $k$-th nearest region. ${ }^{3}$ Market size indicates the mass of consumers, tradable goods retailers and potential producers headquartered in that region.

\footnotetext{
${ }^{3}$ For example, $\omega(a, 1)=a, \omega(a, 2)=b, \omega(b, 2)=a$, and $\omega(c, 3)=a$.
} 
This formulation reflects both market sizes and pure segmentation between any two markets. All else equal, a larger market will attract more producers from all regions, and it will also send more producers to other regions. To these market size forces we add the bias parameter, $\beta_{r k}$, which may limit the trade potential between region pairs. This specification allows us to define a benchmark of what it means for two regions to be fully open to trading with each other $\left(\beta_{r k}=1\right)$, while accounting for relative size differences. We borrow this functional form from the labor market literature on search, where it was first introduced by den Haan, Ramey, and Watson (2000).

The export bias parameters $\beta_{r k}$ may capture informational advantages that ease access to the chain of distribution in certain markets, or external barriers that make transacting with firms located outside one's own network more difficult. They are specific to each source-destination pair and may be asymmetric across region pairs. For simplicity, we assume that these bias parameters are exogenous. The exogeneity assumption can be relaxed without significantly affecting our conclusions, as long as the bias remains orthogonal to short-run relative prices differences between regions. We normalize the home region parameter, $\beta_{r 1}=1$ (essentially assuming that firms always have the option to sell in their own region, though they may choose not to) and we will use data on prices and trade volumes to estimate the remaining relative segmentation parameters. Figure 1 displays the multi-region economy and the export bias rates of producers headquartered in region $a$.

It is useful to note that this notion of segmentation allows for asymmetric frictions across market borders. It may be the case that producers from region $r$ export easily to region $r^{\prime}$, while at the same time region $r^{\prime}$ producers encounter high frictions in exporting to region $r$. This flexibility in turn allows for asymmetries in both pricing patterns and trade flows across borders, consistent with the empirical evidence discussed in more detail in Section 3.

Equilibrium Densities: The export potential between regions is incorporated into the retailers' search process, determining the distribution of producer prices from which retailers in each region can sample. Equilibrium in each region is associated with an 
equilibrium distribution of producer prices and an equilibrium retailer reservation price. Pricing to market arises from producers selling in regions with different reservation prices. The constant returns to scale technology implies that producers solve their profit maximization problem region-by-region. Retailers search only in their own region, and the distribution of producer prices that they face depends on the mix of producers active in that region. Depending on this mix, each region has its own reservation price. The cumulative distribution of prices posted by suppliers from region $r$ in relative region $k$ is

$$
F_{r k}(\widehat{p})=\left\{\begin{array}{lll}
G_{r}\left(\frac{\widehat{p}}{\mu}\right) & \text { if } & \widehat{p} \leq \bar{r}_{\omega(r, k)} \\
1 & \text { if } & \widehat{p}>\bar{r}_{\omega(r, k)}
\end{array}\right.
$$

Exchange Rate Determination: We make assumptions that permit a simple model of the link between exchange rates and real labor costs. In particular, we assume that money demand follows a standard velocity equation, with fixed velocity normalized to one. Under these assumptions,

$$
\begin{aligned}
& P_{T}^{u s} Y_{T}^{u s}+P_{N}^{u s} Y_{N}^{u s}=M^{u s}, \\
& P_{T}^{c a} Y_{T}^{c a}+P_{N}^{c a} Y_{N}^{c a}=e M^{c a},
\end{aligned}
$$

where the left hand side gives the value of each country's total output in U.S. dollars, $M$ is money supply in the country, and an increase in the nominal exchange rate $e$ represents a depreciation of the U.S. dollar.

We also assume that wages in each country incompletely adjust each period to their flexible wage value. That is, we assume that the prevailing nominal wage in country $k$ is given by

$$
W^{k}=\mu_{w} W_{s s}^{k}+\left(1-\mu_{w}\right) W_{\text {flex }}^{k},
$$

where $W_{s s}^{k}$ is the nominally fixed wage that is state-invariant and $W_{\text {flex }}^{k}$ is the flexible equilibrium wage given by the household's optimality condition for labor supply in country $k$. We introduce sticky wages and persistence in our otherwise static model in 
order to generate both substantial fluctuations in the exchange rate and differences in real unit labor costs between countries, consistent with the evidence of Burstein and Jaimovich (2012).

Shocks and Heterogeneity: We include three sources of exogenous variation, each of which play an important role in driving observed levels of price dispersion.

First, we assume idiosyncratic producer productivity for each good $A_{i j}$ is drawn independently each period from a log-normal distribution with mean zero and country-

specific variance $\sigma_{r}^{2}$. These productivity shocks drive price heterogeneity within and across regions in our economy and similar assumptions appear frequently in the related literature.

Second, we assume that the elasticity of substitution among varieties fluctuates independently across the sectors $i$ and countries $c$. In particular, we assume that $\eta_{i c}=$ $\bar{\eta} \exp \left(\xi_{i c}\right)$, with $\xi_{i c}$ drawn from a normal distribution with mean zero and variance $\sigma_{\eta}^{2}$. Because these shocks average out across sectors, they are a source of cross-country price dispersion but are not associated with aggregate fluctuations in the economy.

Third, we assume that the relative money supply $M^{u s} / M^{c a}$ is exogenous and follows an $A R(1)$ process with persistence $\rho_{m}$ and standard deviation of innovations $\sigma_{m}$. Given our assumption of wage stickiness, these nominal shocks drive realistic fluctuations in the real exchange rate and are important for the model's ability to capture observed correlations in cross-country price changes.

\subsection{Identification of Regional and National Frictions}

Our goal is to estimate the bias parameters $\beta_{r k}$ within and across countries. We proceed by imposing within-country symmetry in terms of the sizes of regions, the structural parameters, and the size of the bias. Internally, this means that we assume it is just as easy for producers from region $a$ to sell to retailers in region $b$ as it is for producers from region $b$ to sell to retailers in region $a$ (and likewise for the regions in Canada). Internationally, this means that producers from either region of one country 
find it just as easy (or hard) to sell to either region of the other country. Regional within-country symmetry is supported by evidence in Gopinath et al. (2011) that price differentials in levels are centered around zero within U.S. and Canadian regions, and in Burstein and Jaimovich (2012), who show that average changes in relative prices within these countries are zero. ${ }^{4}$

While a simplification, these assumptions imply that when estimating our trade frictions on the data we are estimating average country specific bias parameters rather than source-destination regions-specific bias parameters. Hence, we use data to identify four bias parameters: the average bias between U.S. regions $\beta_{a 2}$, the average regional bias between Canadian regions $\beta_{c 2}$, the bias that American suppliers face when attempting to sell in either one of the two Canadian regions $\beta_{a 3}$, and the bias that Canadian suppliers face in the American regions $\beta_{c 3}$.

To take the model to the data, we define a measure of Canadian national bias $X_{c a}$ as the probability of an American supplier accessing the Canadian market, relative to that of a Canadian supplier. Analogously, $X_{u s}$ is the American national bias, and these two market access variables are composites of regional and international biases, given by

$$
X_{u s} \equiv \frac{2 \beta_{c 3}}{1+\beta_{a 2}} \text { and } \quad X_{c a} \equiv \frac{2 \beta_{a 3}}{1+\beta_{c 2}}
$$

In Section 3, we parameterize the model to target price dispersion and cross-country trade moments, to identify these national bias parameters. We then use these estimates of composite trade frictions together with internal trade data to separately identify the within-country regional bias and any additional bias that comes from crossing the border. We use the internal import share of region a defined as the demand in the region satisfied by the producers from region $b$, as a fraction of that demand satisfied by producers from regions $a$ or $b$. The model implies that the internal import shares are pinned down by

$$
\phi_{a}=\frac{\beta_{a 2}}{1+\beta_{a 2}} \text { and } \phi_{c}=\frac{\beta_{c 2}}{1+\beta_{c 2}} .
$$

\footnotetext{
${ }^{4}$ In Section 3 we document the robustness of our results to the definition of regions inside each country.
} 
Hence, using price and quantity data, equations (25) and (26) identify the bias parameters for each country.

We underscore that data on the distribution of price dispersion within and across countries can only be used to identify the composite national bias parameters, $X_{u s}$ and $X_{c a}$. Such data cannot distinguish the source of segmentation between bias toward one's own region and bias toward one's own country. Once we allow for the possibility of regional trade frictions, the price dispersion statistics that have often been taken to indicate large frictions and strong segmentation at the national border cannot disentangle the additional segmentation at the national border from that at the regional border inside the country. This lack of identification is not an idiosyncrasy of our model, but rather a feature common to a wide class of models that feature pricing to market with symmetric markets inside countries. This concern is mentioned by Burstein and Jaimovich (2012). Here we formalize it, in the context of our model, and furthermore, in the next section, we provide actual estimates of the relative strength of these two levels of segmentation.

\section{Segmentation Estimates}

We use both price dispersion and trade flows data to identify the export bias parameters that characterize the nature of trade asymmetries within each country and across countries. Our estimates provide a more nuanced characterization of the pattern of trade frictions compared with estimates that are based on a single segmentation parameter between country pairs (for instance in terms of the size of the border between two countries). They also enable us to disentangle the degree of segmentation that is truly coming from the national border from the segmentation that exists at the regional level and to show that, if not accounted for, regional segmentation significantly distorts estimates of national trade barriers. 


\subsection{Data}

We use data for the United States and Canada due to comparability (the two economies are similar in terms of structure and level of development, operate inside a free-trade agreement, and also share a language and a physical border, so that one might expect a relatively small degree of market segmentation) and also to ease comparisons with other work that has used data from these two countries to quantify the severity of international trade frictions.

For all price dispersion measures, we target the statistics reported by Burstein and Jaimovich (2012), because their product-level data sheds light on price dispersion both within and across regions of different countries. The statistics are based on micro data from a major retail chain that operates hundreds of stores in multiple Canadian provinces and U.S. states, hence we can map the data to our multi-region two-country structure. Moreover, the authors collect information on the country of production, and report price statistics separately for each origin-destination country pair. These cuts of the data enable us to characterize heterogeneity in price dispersion across countries for a given set of producers, and also within a country, across products coming from different source countries. Both of these dimensions are needed in order to isolate the role of segmentation as distinct from the role played by different destinations being subjected to different shocks and characterized by different market structures.

The statistics are constructed using the weekly wholesale prices of thousands of products for the period 2004-2006. This time frame is relevant to our question, since during this period the U.S. dollar depreciated by $12 \%$ relative to the Canadian dollar. We use the statistics for traded products that are "broadly matched" across all pricing regions. There are 14 pricing regions in Canada and 85 pricing regions in the United States. Broad matches are defined using items within product categories that have the same brand, manufacturer, and at least one other product characteristic. ${ }^{5}$

\footnotetext{
${ }^{5}$ Burstein and Jaimovich (2012) also report versions of these statistics with narrower, more exact matches. But since the differences in dispersion statistics are fairly modest across the different product classification methods, our segmentation estimates are robust to targeting these other matches. See Burstein and Jaimovich (2012) for additional details about the data coverage. Gopinath et al. (2011) also use data from the same chain in their study of relative costs and markup differences across the
} 
We pause briefly here to describe how we will link the model environment to these data. Since the goods in the data are matched, branded goods (e.g. a two-liter bottle of Canada Dry Ginger Ale), we let the "variety" dimension $\nu$ correspond to the store where the good is sold. Hence, cross-store price differences of Canada Dry Ginger Ale are comparisons of $p(i, \nu)$ to $p\left(i, \nu^{\prime}\right)$. In this context, it is most natural to interpret different firms indexed by $(i j)$ and $\left(i j^{\prime}\right)$ as wholesalers competing to supply retailers with identical products at (potentially) different prices.

The pricing statistics that we use to pin down the parameters of our model concern the volatility of changes in product-level real exchange rates across different region pairs. For any two regions, the product-level real exchange rate $(\mathrm{rer})$ of good $i$ in period $t$ is

$$
d_{i, t}\left(r, r^{\prime}\right) \equiv p_{i, t}(r)-p_{i, t}\left(r^{\prime}\right)-e_{t}\left(r, r^{\prime}\right)
$$

where $p_{i, t}(r)$ is the log price in the local currency of region $r, e_{t}\left(r, r^{\prime}\right)$ is the log of the nominal exchange rate $(N E R)$ between regions $r$ and $r^{\prime}$, and an increase in $e_{t}\left(r, r^{\prime}\right)$ represents a depreciation of the currency in location $r$. In the absence of frictions, $d_{i, t}$ would be zero (absolute $P P P$ ) or, if there are permanent differences across locations, a nonzero constant (relative $P P P$ ). Instead, product-level real exchange rates are very volatile. Moreover, the expenditure-weighted aggregated real exchange rate $(R E R)$ closely tracks the nominal exchange rate. ${ }^{6}$

We complement the regional price dispersion statistics with inter-provincial trade data from Statistics Canada, interstate U.S. trade data from the Commodity Flow Survey (CFS) produced by the United States Department of Transportation, cross-country gross trade flows in goods from the U.S. Census Bureau and National Income and Product Accounts, and U.S. markup data from the Census Bureau's Wholesale Trade Survey. Since the state-level trade data available from the CFS are from 2007, we use 2007 as our base year for computing all trade quantities and markup levels.

two countries.

${ }^{6}$ This well-known aggregate fact has been reconstructed from micro-level data in various forms, and holds not just for this data set, but across many countries and time periods, for consumer and at-the-dock prices. See Burstein and Gopinath (2014) for a recent review of the evidence. 
Table 1: Baseline Model Parameterization

\begin{tabular}{llll}
\hline Parameter & & Value & Explanation \\
\hline Consumers & & & \\
Share of tradables in consumption & $\phi$ & 0.66 & Standard \\
Inverse of Frisch elasticity of labor supply & $\nu$ & 1 & Standard \\
Multiplicative factor in labor disutility & $\psi$ & 5 & Implies $L^{s s}=0.4$ \\
Elasticity of sub across traded goods & $\rho$ & 2.427 & Joint optimization \\
Mean elasticity of sub across varieties & $\bar{\eta}$ & 5.036 & Joint optimization \\
St. dev. of elasticity across varieties & $\sigma_{\eta}$ & 0.165 & Joint optimization \\
& & & \\
Retailers & & & \\
U.S. retailers search cost & $\kappa_{u s}$ & 0.005 & Joint optimization \\
Canadian retailers search cost & $\kappa_{c a}$ & 0.002 & Joint optimization \\
Producers & & & \\
U.S. st. dev. of id. productivity shocks & $\sigma_{u s}$ & 0.128 & Joint optimization \\
Canadian st. dev. of id. prod. shocks & $\sigma_{c a}$ & 0.088 & Joint optimization \\
Foreign relative to domestic access to U.S. & $X_{u s}$ & 0.134 & Joint optimization \\
Foreign rel. to domestic access to Canada & $X_{c a}$ & 0.451 & Joint optimization \\
Aggregates & & & \\
Relative country sizes & & & \\
Persistence of relative money supply & $s_{u s} / s_{c a}$ & 8 & U.S./Canada production \\
St. dev. of relative money supply shocks & $\sigma_{m}$ & 0.950 & 0.95 autocorrelation of $N E R$ \\
Nominal wage rigidity & $\mu_{w}$ & 0.85 & Standard \\
\hline
\end{tabular}

Note: The targets for the joint optimization are described in Table 2.

\subsection{Parameters and Targets}

Table 1 presents the parameter values of the model and Table 2 presents the targets for the joint optimization. In Table 1, the top panel shows the parameters that characterize consumer preferences. The first three parameters are standard. We fix the share of traded goods in the final good consumption aggregator to $\phi=0.66$, which is a value commonly used in the literature. The inverse Frisch elasticity of labor supply is $\nu=1$ and the multiplicative factor in labor disutility is $\psi=5$, which yields a steady state labor supply value equal to 0.4 . 
More important for our results are the parameters that govern consumers' elasticity of demand, which we estimate jointly with the country-specific retailer and producer parameters shown in the middle panels. We set the values for these parameters so as to minimize the squared deviations from the data of the nine moments on U.S.-Canada trade and on relative price differences listed in Table 2. We estimate an elasticity of substitution at the sector level $\rho=2.4$, a mean elasticity of substitution between varieties in a sector $\bar{\eta}=5.0$, and the standard deviation of this elasticity across sectors, $\sigma_{\eta}=0.16$. The retailers' search costs are estimated at $\kappa_{u s}=0.005$ and $\kappa_{c a}=0.002$. The estimated search costs are small, representing $1.6 \%$ of revenues for U.S. retailers and $0.6 \%$ of revenues for Canadian producers. Together with the estimated elasticity parameters, the search costs play an important role in determining firms' pricing power. Although modest, the estimated values limit markups well below their steady-state monopoly value, but still allow for the substantial price dispersion seen in the data. In particular, we match the sales-weighted unconditional markup of U.S. producers of $14.8 \%$.

For the level of idiosyncratic productivity dispersion, we estimate $\sigma_{u s}=0.128$ and $\sigma_{c a}=0.088$. The relatively larger dispersion across U.S. firms is important for matching the differential levels of within-country price dispersion. In turn, matching this differential is necessary for a proper structural identification of the border effect as distinct from country heterogeneity, as argued by Gorodnichenko and Tesar (2009). For price dispersion within and across markets, we target the standard deviation of changes in the product-level real exchange rate $\sigma_{k, x}^{\Delta d}$, computed across country pairs $\{k, x\}$ for each source country $k=\{u s, c a\}$ (which indicates the home of the producer), and destination country $x=\{u s, c a, a l l\}$ (which indicates where the product is sold), where all denotes that the standard deviation is computed for all region pairs across both countries. The values for these statistics are taken from Burstein and Jaimovich (2012).

The numbers illustrate two facts. First, deviations from relative price parity are larger when comparing relative prices across countries than within. Second, these de- 
Table 2: Targets for Joint Parameter Optimization

Statistic

Data Base Regional Open No PTM

$\begin{array}{lllllll}\text { Share of US demand met by CA firms } & \Gamma_{u s} & 0.021 & 0.021 & 0.028 & 0.060 & 0.022 \\ \text { Share of CA demand met by US firms } & \Gamma_{c a} & 0.175 & 0.180 & 0.235 & 0.440 & 0.191 \\ \text { Sales-weighted US producer markup } & \bar{\mu}_{u s} & 0.148 & 0.148 & 0.149 & 0.148 & 0.244 \\ \text { St. dev. of product-level rer changes } & & & & & & \\ \text { across US regions, US-made goods } & \sigma_{u s, u s}^{\Delta d} & 0.080 & 0.084 & 0.086 & 0.092 & 0.256 \\ \text { across CA regions, US-made goods } & \sigma_{u s, c a}^{\Delta d} & 0.060 & 0.052 & 0.061 & 0.059 & 0.256 \\ \text { across all regions, US-made goods } & \sigma_{u s, a l l}^{\Delta d} & 0.130 & 0.145 & 0.149 & 0.170 & 0.269 \\ \text { across US regions, CA-made goods } & \sigma_{c a, u s}^{\Delta d} & 0.100 & 0.091 & 0.067 & 0.016 & 0.177 \\ \text { across CA regions, CA-made goods } & \sigma_{c a, c a}^{\Delta d} & 0.040 & 0.044 & 0.036 & 0.005 & 0.177 \\ \text { across all regions, CA-made goods } & \sigma_{c a, a l l}^{\Delta d} & 0.170 & 0.138 & 0.138 & 0.160 & 0.195\end{array}$

Note: Product-level real exchange rate moments are from Table 5, Panel B of Burstein and Jaimovich (2012). The baseline parameterization (Base) sets model parameters to values that minimize the squared deviations from the data of the nine moments listed in the table. The Regional parameterization imposes regional-only export bias, setting $\beta_{a 3}=\beta_{a 2}$ for American suppliers and $\beta_{c 3}=\beta_{c 2}$ for Canadian suppliers. The Open parameterization imposes no bias either internally or internationally $\left(\beta_{r k}=1\right)$. The No PTM parameterization imposes arbitrarily high search costs for retailers, so that producers charge constant (monopoly) markups.

viations are larger within the United States compared with Canada, regardless of the home country of the producer. The model reproduces these differences primarily by setting asymmetric productivity dispersion and retailer search costs across the two countries. In the data, the standard deviation for products made in the U.S. is $13 \%$ across all regions versus $8 \%$ across U.S. regions and 6\% across Canadian regions, and our model generates values equal to $14.5 \%, 8 \%$ and $5 \%$, respectively. For products made in Canada, the standard deviations are 17\% across all regions, $10 \%$ inside the U.S., and $4 \%$ in Canada, and the model yields 14\%, $9 \%$ and 4\%, respectively.

The most important estimates are the national bias parameters, defined in equation (25) and measuring the probability of a foreign producer (or distributor) accessing 
the domestic country, relative to that of a domestic producer (from either region). We estimate $X_{u s}=0.134$ for relative Canadian access to the United States and $X_{c a}=0.451$ for the access of American firms to Canada. These bias parameters affect both the price dispersion statistics and the share of domestic U.S. demand met by imports from Canada and the equivalent object from the Canadian perspective. United States imports from Canada account for $\Gamma_{u s}=2.1 \%$ of final U.S. demand, while imports by Canada of goods from the United States account for $\Gamma_{c a}=17.5 \%$ of domestic demand in Canada. Our model matches the U.S. parameter exactly, while generating a slightly higher import share for Canada, at $18.0 \%$.

These national bias estimates are both substantially less than one, implying a strong home country bias. Matching the data on both trade and price dispersion requires that both the United States and Canada be significantly more open to their own producers than to producers from the other country. This result merely confirms a long line of work that has documented that such a home bias exists and can be quite large (going back to the seminal work of McCallum (1995) and Engel and Rogers (1996)). However, our estimates also uncover substantial asymmetry: Canada appears to be much more open to U.S. products than the United States is to Canadian products, controlling for country size differences. We estimate that U.S. firms are about three times more likely to access the Canadian market, compared with Canadian firms' access to the U.S. market.

Lastly, the bottom panel of the table shows the aggregate parameters, which are standard. We set the relative size of the two countries $s_{u s} / s_{c a}=8$, to match the ratio of goods production between the United States and Canada. We select the volatility and persistence of relative money supply shocks to match an unconditional auto-correlation of the nominal exchange rate of 0.95 and a standard deviation of changes in the nominal exchange rate of 3.0\%, as reported by Burstein and Jaimovich (2012). These targets imply $\rho_{m}=0.95$ and $\sigma_{m}=0.057$. We normalize the fixed component of the nominal wage to be equal to the equilibrium wage when aggregate shocks are at their steadystate values, and we set the adjustment parameter $\mu_{w}=0.85$ to capture large short-run 
stickiness in nominal wages. Persistence in relative money supply and sticky nominal wages generate both substantial fluctuations in the exchange rate and differences in real unit labor costs between countries. Reducing the degree of nominal wage rigidity increases the volatility of the nominal exchange rate and also makes price changes more correlated across countries.

\subsection{Bias in Trade}

We now turn to our main result, estimating regional versus national export bias. To disentangle the regional from the national bias, we use data for internal trade for ten Canadian provinces plus three territories, and for all U.S. states. We combine these geographic units into two regions for each country. Geographic distinctions (for instance, East versus West) provide a natural way to split the two countries, but in order to ensure that our choice of geography is not influencing our results, we consider a much broader set of regional definitions. For the United States, we first combine the states into 12 different regions, according to the Department of Transportation subregion classification. We then consider all possible two-region splits of the 12 regions. Among these, we keep only those splits for which the total economic output of each region is within $10 \%$ of the other, thus aligning with our model of assumption of equalsize regions. ${ }^{7}$ This procedure yields 464 roughly equal-sized 2-region splits of the United States (out of the $2^{11}$ possible splits). For Canada, we follow an identical procedure, after first combining the data for the three territories of Canada (Northwest Territories, Nunavut, and Yukon), and considering 10 provinces plus 1 combined territory. We obtain 108 2-region splits of Canada (out of the possible $2^{10}$ region definitions).

Baseline Segmentation: Table 3 reports our estimates for the degree of regional versus national segmentation for the United States and Canada. The table reports the median, minimum and maximum value of the export bias estimates, where the statistics are computed over all similarly sized regional splits of the two countries. We

\footnotetext{
${ }^{7}$ Our computation of the underlying bias parameters takes into account the actual size differences in the alternative region definitions, however small.
} 
Table 3: Estimated Regional and National Bias Parameters

\begin{tabular}{lccccccc}
\hline & \multicolumn{3}{c}{ United States } & \multicolumn{3}{c}{ Canada } \\
& & Median & Min & Max & Median & Min & Max \\
\hline & & & & & & & \\
Cross-region bias & $\beta_{r 2}$ & 0.32 & 0.24 & 0.39 & 0.14 & 0.12 & 0.16 \\
Cross-country bias & $\beta_{r 3}$ & 0.26 & 0.25 & 0.26 & 0.09 & 0.08 & 0.09 \\
\hline
\end{tabular}

Note: Within-region bias is normalized to $\beta_{r 1}=1$. Cross-region bias is the relative bias against the "away" region of one's own country. Cross-country bias is the bias against either one of the two foreign regions, relative to one's own region. The median, minimum and maximum values are computed over all similarly-sized regional splits of each country.

find a median value for the average U.S. regional bias of $\beta_{a 2}=0.32$. This means that an American supplier is about three times (1/0.32) more likely to sell to their own region than to the other region in the United States. How we split the United States into two equal sized regions matters to some extent, with $\beta_{a 2}$ varying between 0.24 and 0.39 , but the main takeaway is that there is considerable segmentation of regions within the United States. Crossing the national border further reduces access. We find a median value for the average U.S. national bias of $\beta_{a 3}=0.26$, and there is virtually no variation in this estimate, regardless of regional splits. Hence, an American producer is about four times more likely to have access to its own region than either Canadian region. But overall, the bulk of the segmentation (the distance from the full access benchmark $\left.\beta_{a 1}=1\right)$ comes from home bias at the regional level.

Market segmentation faced by Canadian producers is larger than that faced by American producers, both internally and across the border. We estimate a median value for the Canadian regional bias of $\beta_{c 2}=0.14$ and for the Canadian national bias of $\beta_{c 3}=0.09$, meaning that a Canadian producer is seven times more likely to sell in its own region than in the "away" Canadian region, and 11 times more likely to sell in its own region than in either U.S. region. Once again, regional home bias is a major component of the national home bias, and interestingly, it appears to be more severe for Canadian producers. 
The Relevance of Regional Bias: Our results indicate that segmentation within countries is non-negligible and is in fact responsible for a big portion of the segmentation observed across countries. To put the strength of this result in context, consider an experiment in which, rather than using trade and price data to pin down segmentation across countries, we instead assume that the degree of cross-country bias is the same as that within countries, thereby maintaining only regional bias. We run the model imposing the restriction that an American supplier has the same access to a Canadian region as it does at home, to the "away" U.S. region, and similarly for the Canadian supplier, namely, that $\beta_{u s, 3}=\beta_{u s, 2}$ and $\beta_{c a, 3}=\beta_{c a, 2}$. We use the median value for the regional bias parameters, and we report the results in the column titled "Regional" of Table 2. In this experiment, both countries are more open to each other, with import shares increasing from $2.1 \%$ to $2.8 \%$ for the United States and from $18.0 \%$ to $23.5 \%$ for Canada. But the price dispersion moments are only marginally affected. Overall, the data are not far from the case in which we impose that all trade frictions come from a region-level bias that is symmetric for all regions, be they in one's own country or not.

The Degree of Cross-Country Openness: Where do our estimates lie on the continuum between full openness and autarky? Consider the extreme in which we remove both internal and international trade biases. In this case, the key determinants of trade flows and deviations from price parity across the two countries become relative market sizes and relative markups. The column of Table 2 titled Open reports the model-implied moments from this counterfactual exercise. Not only would trade levels be much higher between the two countries, but price dispersion would also increase, since lower trade barriers enable producers with more dispersed costs to be active.

The contrast with the baseline economy demonstrates that cross-border market frictions have a substantial effect on firms' pricing decisions and serve to compress what, according to our model, would otherwise be even larger cross-border pricing differentials. On the other hand, the Regional calibration demonstrates that the two economies are segmented to a significant degree due to internal barriers. Taken together, these two counterfactual exercises suggest partial market segmentation that supports 
the finding of Gopinath et al. (2011) that international markets are strongly segmented; but unlike these authors, we attribute much of this segmentation to regional, rather than international frictions.

The Role of Pricing-to-Market: In the model, the distributions of prices differ across countries because of pricing to market by each producer active in the two markets and also because of differences in the composition of active producers. Pricing to market arises due to differences between countries in structural parameters (such as the dispersion in local producer productivities) and shock realizations (such as aggregate demand). The partial segmentation across markets enables producers to post different prices in different countries in response to these structural differences. Moreover, differences in market sizes and bias parameters imply that the mass of producers from different regions differs across destination markets, resulting in compositional differences across markets.

We investigate how strong pricing-to-market is in our model by considering an alternative parameterization in which search costs are high enough that the threat of retailer search is effectively shut down. In this case, producers always charge a constant monopoly markup relative to their marginal cost. The last column of Table 2 shows that under this calibration price dispersion is much larger, as the threat of search no longer limits markups. More importantly, the degree of additional price dispersion created by the border largely disappears, with cross-border price dispersion only marginally higher than the country-level dispersion numbers for the United States and Canada. This calibration indicates that pricing-to-market plays a very important role in explaining cross-border price differentials, a finding that is consistent with both Gopinath et al. (2011) and Burstein and Jaimovich (2012).

\section{Robustness}

Non-targeted Moments: Table 4 shows that the model can match other moments in the data as well. A particularly striking fact about the micro data is that price 
Table 4: Non-Targeted Moments

\begin{tabular}{|c|c|c|c|c|c|c|}
\hline Statistic & Symbol & Data & Base & Regional & Open & No PTM \\
\hline \multicolumn{7}{|c|}{ Correlation of product-level price changes } \\
\hline across US regions, US-made goods & $\rho_{u s, u s}^{\Delta p}$ & 0.68 & 0.72 & 0.71 & 0.70 & 0.10 \\
\hline across CA regions, US-made goods & $\rho_{u s, c a}^{\Delta p}$ & 0.81 & 0.85 & 0.82 & 0.89 & 0.10 \\
\hline across all regions, US-made goods & $\rho_{u s, a l l}^{\Delta p}$ & 0.05 & 0.02 & 0.02 & 0.01 & 0.007 \\
\hline across US regions, CA-made goods & $\rho_{c a, u s}^{\Delta p}$ & 0.74 & 0.64 & 0.79 & 0.99 & 0.20 \\
\hline across CA regions, CA-made goods & $\rho_{c a, c a}^{\Delta p}$ & 0.89 & 0.88 & 0.93 & 0.999 & 0.20 \\
\hline across all regions, CA-made goods & $\rho_{c a, a l l}^{\Delta p}$ & 0.04 & 0.04 & 0.03 & 0.01 & 0.02 \\
\hline Correlation of RER and NER & $\rho_{\text {rer }, \text { ner }}$ & & 0.985 & 0.986 & 0.99 & 0.99 \\
\hline Sales-weighted CA producer markup & $\bar{\mu}_{c a}$ & & 0.15 & 0.14 & 0.09 & 0.24 \\
\hline
\end{tabular}

Note: Product-level real exchange rate data moments are from Table 5, Panel B of Burstein and Jaimovich (2012). In the no segmentation (Open) calibration, all bias parameters are equal to 1 . In the no pricing pricing-to-market (No PTM) calibration, search costs are increased to a level that precludes retailer search, so that producers charge constant (monopoly) markups. 
Table 5: Alternative Regional and National Bias Parameters

\begin{tabular}{lccccccc}
\hline & \multicolumn{3}{c}{ United States } & \multicolumn{3}{c}{ Canada } \\
& & Median & Min & Max & Median & Min & Max \\
\hline & & & & & & & \\
Cross-region bias & $\beta_{r 2}$ & 0.41 & 0.30 & 0.51 & 0.18 & 0.15 & 0.20 \\
Cross-country bias & $\beta_{r 3}$ & 0.26 & 0.26 & 0.27 & 0.09 & 0.09 & 0.10 \\
\hline
\end{tabular}

Note: Alternative bias estimates for the case in which trade is $20 \%$ higher than reported in the aggregate data. Within-region bias is normalized to $\beta_{r 1}=1$. Cross-region bias is the relative bias against the "away" region of one's own country. Cross-country bias is the bias against either one of the two foreign regions, relative to one's own region. The median, minimum and maximum values are computed over all similarly-sized regional splits of each country.

changes are far more correlated within countries than across countries: within-country correlations of price changes range between $68 \%$ and $89 \%$, while across, countries, the correlation is $5 \%$ or less. This fact has been taken as evidence in favor of large frictions across countries. But our model is able to replicate these facts, as well as generating a high positive correlation for real and nominal aggregate exchange rates, even though frictions are mostly concentrated at the regional level.

Another confirmation of the relevance of trade barriers coming from the regional bias and pricing to market is given by the average sales-weighted Canadian markup implied by the model, which is $15 \%$ in the baseline calibration and $14 \%$ in the regionalbarriers-only calibration. But the number shoots up to $24 \%$ in the no-pricing-to-market case and drops to as little as $9 \%$ in the case of no trade barriers, as competition from the United States puts pressure on average markups in Canada.

The Importance of Trade Flows: We estimate very strong segmentation based on detailed micro price data but fairly aggregated trade data across regions. One important question is how sensitive our results might be to using more disaggregated trade data, for instance at the same level of aggregation as the data underlying our price statistics. In the absence of such data, we instead ask the following question: How much would our international trade bias estimates be affected if the internal trade data were 
underestimated by $20 \%$ ? Table 5 reports the resulting segmentation estimates, which confirm that internal regional bias would drop significantly, with firms now more likely to transact across regions within each country. However, the degree of international segmentation would be virtually unchanged.

\section{Conclusion}

We have demonstrated that a model of price dispersion via retailer search can replicate the most prominent facts about good-level real exchange rates without relying on market segmentation induced by the international border. Evidence on intranational trade from the United States and Canada strongly indicates that in fact the national border plays a rather limited role in segmenting markets. Instead, internal regional segmentation seems the much larger source of market segmentation. Hence, there is substantial scope for further study of intra-national barriers to the flow of goods.

Beyond the application to the particular case of United States-Canada bilateral trade, identifying the degree of market segmentation in other contexts is also likely to require data on variables other than prices, most notably trade quantities. Although the model we have presented here incorporates a reduced-form wage friction, we leave for future work the introduction of a micro-founded nominal price stickiness. Although it cannot account for the data on its own, it is possible that in a dynamic setting, price stickiness interacts in an important way with our search friction, supporting the persistence of price dispersion. Our work is also complementary to work that has studied the integration of factor markets, which are also significantly segmented even within countries.

One possible objection to the approach taken here is that by eliminating regionlevel shocks we may have eliminated a potential source of identification that would arise if we could compare price differences within and across regions, as well as prices across the international border. Our model has been constructed to match the findings of Gopinath et al. (2011) that price differences at regional borders are small, and it 
seems unlikely to us that such shocks play an important role in generating the data. Nevertheless, the results regarding the relative degree of within- and across-country segmentation would not be overturned even by relaxing this assumption. To see this, note that to the extent that the distribution of prices differs more across regions than within, firms drawing cross-region prices will optimally stop and purchase from across the regional border more often than in the same model without such differences. This will lead, other things equal, to a larger degree of within-country trade. In order to match the low observed level of internal trade, then, the model would require an even greater degree of within-country market segmentation. Thus, even if a within/acrossregion comparison of prices could offer some identifying information regarding the degree of internal segmentation, it would not lead to a qualitative change in our conclusion regarding the relative importance of within-country market segmentation.

A second possible objection to our general modeling strategy is our strong assumption regarding the exogeneity of bias parameters with respect to the price distributions in each country. While this assumption plays an important role in keeping the environment tractable, it is important to note that the model maintains two channels that allow for substantial expenditure switching as relative costs across the countries fluctuate. First, conditional on settling on a supplier, elastic final demand implies that retailers who land at producers with relatively low costs purchase relatively large quantities. Second, the presence of good-level shocks, combined with the endogenous decision of firms to shut down, leads to a smaller mass of price-posting firms in the country with relatively higher costs, shrinking the probability that firms will sample suppliers from that country. To demonstrate that the channels lead to a qualitatively reasonable degree of expenditure switching, we regressed the log of the quantity of imports on a constant, the log of total domestic traded good absorption, and the log of the nominal exchange rate in each country. We find that a $1 \%$ depreciation of the United States dollar leads to a roughly $0.8 \%$ fall in United States imports of Canadian goods and a roughly $1.9 \%$ increase in Canadian imports of United States goods. We nevertheless leave for future research the endogenization of the bias parameters. 


\section{References}

Alessandria, G. (2004). International Deviations from the Law of One Price: The Role of Search Frictions and Market Share. International Economic Review 45(4), 1263-1291.

Alessandria, G. (2009). Consumer Search, Price Dispersion, and International Relative Price Fluctuations. International Economic Review 50(3), 803-829.

Alessandria, G. and J. P. Kaboski (2011). Pricing-to-Market and the Failure of Absolute PPP. American Economic Journal: Macroeconomics 3(1), 91-127.

Anderson, J. E. and E. van Wincoop (2003). Gravity With Gravitas: A Solution to the Border Puzzle. American Economic Review 93(1), 170-192.

Atkeson, A. and A. Burstein (2008). Pricing-to-Market, Trade Costs, and International Relative Prices. American Economic Review 98(5), 1998-2031.

Baxter, M. and A. Landry (2012). IKEA: Product, Pricing, and Pass-Through. Working Paper, Federal Reserve Bank of Dallas.

Berger, D., J. Faust, J. H. Rogers, and K. Steverson (2012). Border Prices and Retail Prices. Journal of International Economics 88(1), 62-73.

Boivin, J., R. Clark, and N. Vincent (2012). Virtual Borders. Journal of International Economics 86(2), 327-335.

Broda, C. and D. E. Weinstein (2008, May). Understanding International Price Differences Using Barcode Data. Working Paper 14017, National Bureau of Economic Research.

Burdett, K. and K. L. Judd (1983). Equilibrium price dispersion. Econometrica: Journal of the Econometric Society 51(4), 955-970.

Burstein, A. and G. Gopinath (2014). International Prices and Exchange Rates. In G. Gopinath, E. Helpman, and K. Rogoff (Eds.), Handbook of International Economics, Volume 4, Amsterdam, pp. 391-451. Elsevier.

Burstein, A. and N. Jaimovich (2012). Understanding Movements in Aggregate Product-Level Real-Exchange Rates. Working paper, UCLA.

Candian, G. (2015). Information Frictions and Real Exchange Rate Dynamics. Working paper, Boston College.

Chen, N. (2004). Intra-national Versus International Trade in the European Union: Why do National Borders Matter? Journal of International Economics 63(1), 93118. 
Crucini, M. J. and C. I. Telmer (2012, April). Microeconomic Sources of Real Exchange Rate Variability. Working Paper 17978, National Bureau of Economic Research.

De Loecker, J., P. K. Goldberg, A. K. Khandelwal, and N. Pavcnik (2015). Prices, Markups and Trade Reform. Econometrica forthoming.

den Haan, W. J., G. Ramey, and J. Watson (2000). Job destruction and propagation of shocks. The American Economic Review 90(3), 482-498.

Diamond, P. A. (1971). A Model of Price Adjustment. Journal of Economic Theory 3(2), 156-168.

Drozd, L. A. and J. B. Nosal (2012). Understanding International Prices: Customers As Capital. American Economic Review 102(1), 364-395.

Eichenbaum, M., N. Jaimovich, and S. Rebelo (2011). Reference Prices and Nominal Rigidities. American Economic Review 101(1), 234-62.

Engel, C. and J. H. Rogers (1996). How Wide is the Border? American Economic Review $86(5), 1112-1125$.

Fitzgerald, D. and S. Haller (2014). Pricing-to-Market: Evidence from Plant-Level Prices. Review of Economic Studies 81(2), 761-786.

Goldberg, P. K. and R. Hellerstein (2008). A structural approach to explaining incomplete exchange-rate pass-through and pricing-to-market. American Economic Review 98(2), 423-29.

Goldberg, P. K. and R. Hellerstein (2013). A Structural Approach to Identifying the Sources of Local Currency Price Stability. The Review of Economic Studies 80(1), $175-210$.

Gopinath, G., P.-O. Gourinchas, C.-T. Hsieh, and N. Li (2011). International Prices, Costs, and Markup Differences. American Economic Review 101(6), 2450-2486.

Gorodnichenko, Y. and L. L. Tesar (2009). Border Effect or Country Effect? Seattle May Not be So Far from Vancouver After All. American Economic Journal: Macroeconomics 1(1), 219-241.

Hillberry, R. and D. Hummels (2003). Intranational Home Bias: Some Explanations. Review of Economics and Statistics 85(4), 1089-1092.

Hillberry, R. and D. Hummels (2008). Trade Responses to Geographic Frictions: A Decomposition Using Micro-data. European Economic Review 52(3), 527-550.

Kaplan, G. and G. Menzio (2015). The morphology of price dispersion. International Economic Review 56(4), 1165-1206. 
McCallum, J. (1995). National Borders Matter: Canada-U.S. Regional Trade Patterns. American Economic Review 85(3), 615-623.

Menzio, G. and N. Trachter (2015). Equilibrium price dispersion with sequential search. Journal of Economic Theory 160, 188-215.

Menzio, G. and N. Trachter (2018). Equilibrium price dispersion across and within stores. Review of Economic Dynamics 28, 205-220.

Millimet, D. L. and T. Osang (2007). Do State Borders Matter For U.S. Intranational Trade? The Role of History and Internal Migration. Canadian Journal of Economics 40(1), 93-126.

Reinganum, J. F. (1979). A Simple Model of Equilibrium Price Dispersion. Journal of Political Economy 87(4), 851-858.

Salop, S. and J. Stiglitz (1977). Bargains and ripoffs: A model of monopolistically competitive price dispersion. The Review of Economic Studies 44, 493-510.

Wolf, H. C. (2000). Intranational Home Bias in Trade. Review of Economics and Statistics 82(4), 555-563. 